II presente documento viene fornito attraverso il servizio NILDE dalla Biblioteca fornitrice, nel rispetto della vigente normativa sul Diritto d'Autore (Legge n.633 del 22/4/1941 e successive modifiche e integrazioni) e delle clausole contrattuali in essere con il titolare dei diritti di proprietà intellettuale.

La Biblioteca fornitrice garantisce di aver effettuato copia del presente documento assolvendo direttamente ogni e qualsiasi onere correlato alla realizzazione di detta copia.

La Biblioteca richiedente garantisce che il documento richiesto è destinato ad un suo utente, che ne farà uso esclusivamente personale per scopi di studio o di ricerca, ed è tenuta ad informare adeguatamente i propri utenti circa i limiti di utilizzazione dei documenti forniti mediante il servizio NILDE.

La Biblioteca richiedente è tenuta al rispetto della vigente normativa sul Diritto d'Autore e in particolare, ma non solo, a consegnare al richiedente un'unica copia cartacea del presente documento, distruggendo ogni eventuale copia digitale ricevuta.

Biblioteca richiedente: Università degli studi di Firenze Biblioteca Biomedica

Data richiesta:

01/09/2015 09:33:06

Biblioteca fornitrice: Biblioteca L. Bergamini - Dipartimento di Neuroscienze

Data evasione: 01/09/2015 10:05:44

Titolo rivista/libro: International journal of psychiatry in clinical practice (Print)

Titolo articolo/sezione: BDNF and Artemin are increased in drug-naive non-depressed GAD patients:preliminary data

Autore/i:

Pallanti S, Tofani T, Zanardelli M, Di Cesare Mannelli L, Ghelardini C

ISSN:

1365-1501

DOI:

Anno:

Volume:

18

Fascicolo:

4

Editore:

Pag. iniziale:

Pag. finale: 
This article was downloaded by: [Universita degli Studi di Torino]

On: 01 September 2015, At: 00:48

Publisher: Taylor \& Francis

Informa Ltd Registered in England and Wales Registered Number: 1072954 Registered office: 5 Howick Place, London, SW1P 1WG

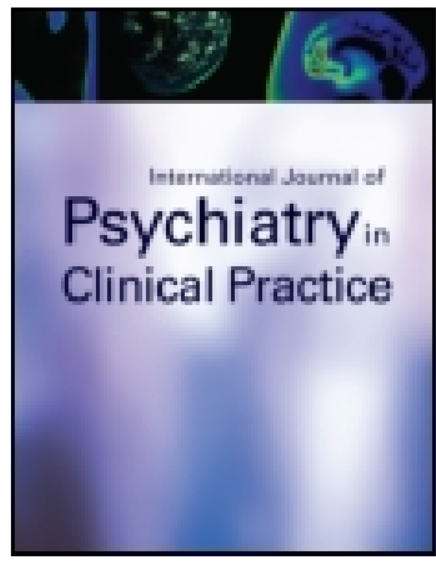

CrossMark
International Journal of Psychiatry in Clinical Practice Publication details, including instructions for authors and subscription information: http:// www.tandfonline.com/loi/ijpc20

\section{BDNF and ARTEMIN are increased in drug-naïve non- depressed GAD patients: Preliminary data}

Stefano Pallanti ${ }^{a b c}$, Tommaso Tofani ${ }^{b}$, Matteo Zanardelli ${ }^{b}$, Lorenzo Di Cesare Mannelli ${ }^{b}$ Carla Ghelardini ${ }^{b}$

${ }^{a}$ UC Davis Department of Psychiatry and Behavioral Sciences, Sacramento, CA, USA

${ }^{b}$ Department of Neurosciences, Psychology, Drug Research and Child Health Neurofarba, Pharmacology and Toxicology Section, and Psychiatric Section, University of Florence, Florence, Italy

${ }^{c}$ Department of Psychiatry and Behavioral Sciences, Albert Einstein College and Montefiore Medical Center, Bronx, NY, USA

Accepted author version posted online: 04 Jul 2014.Published online: 12 Aug 2014.

Click for updates

To cite this article: Stefano Pallanti, Tommaso Tofani, Matteo Zanardelli, Lorenzo Di Cesare Mannelli \& Carla Ghelardini (2014) BDNF and ARTEMIN are increased in drug-naïve non-depressed GAD patients: Preliminary data, International Journal of Psychiatry in Clinical Practice, 18:4, 255-260

To link to this article: http://dx.doi.org/ 10.3109/ 13651501.2014.940051

\section{PLEASE SCROLL DOWN FOR ARTICLE}

Taylor \& Francis makes every effort to ensure the accuracy of all the information (the "Content") contained in the publications on our platform. However, Taylor \& Francis, our agents, and our licensors make no representations or warranties whatsoever as to the accuracy, completeness, or suitability for any purpose of the Content. Any opinions and views expressed in this publication are the opinions and views of the authors, and are not the views of or endorsed by Taylor \& Francis. The accuracy of the Content should not be relied upon and should be independently verified with primary sources of information. Taylor and Francis shall not be liable for any losses, actions, claims, proceedings, demands, costs, expenses, damages, and other liabilities whatsoever or howsoever caused arising directly or indirectly in connection with, in relation to or arising out of the use of the Content.

This article may be used for research, teaching, and private study purposes. Any substantial or systematic reproduction, redistribution, reselling, loan, sub-licensing, systematic supply, or distribution in any form to anyone is expressly forbidden. Terms \& Conditions of access and use can be found at http:// www.tandfonline.com/page/terms-and-conditions 


\title{
BDNF and ARTEMIN are increased in drug-naïve non-depressed GAD patients: Preliminary data
}

\author{
Stefano Pallanti ${ }^{1,2,3}$, Tommaso Tofani ${ }^{2}$, Matteo Zanardelli ${ }^{2}$, Lorenzo Di Cesare Mannelli ${ }^{2}$ \& \\ Carla Ghelardini ${ }^{2}$ \\ ${ }^{1}$ UC Davis Department of Psychiatry and Behavioral Sciences, Sacramento, CA, USA, ${ }^{2}$ Department of \\ Neurosciences, Psychology, Drug Research and Child Health Neurofarba, Pharmacology and Toxicology \\ Section, and Psychiatric Section, University of Florence, Florence, Italy, and ${ }^{3}$ Department of Psychiatry and \\ Behavioral Sciences, Albert Einstein College and Montefiore Medical Center, Bronx, NY, USA
}

\begin{abstract}
Objective. While the role of neuronal and glial plasticity are well established in the pathophysiology of mood disorders, the pattern and measures of neuronal and glial cell line-derived neurotrophic factors are unknown in generalized anxiety disorder (GAD). The present study evaluates brain-derived neurotrophic factor (BDNF) and Artemin (ARTN) plasma levels in GAD patients. Methods. Fourteen drug-naïve GAD patients without major depression were enrolled and plasmatic levels of BDNF and ARTN mRNA were measured by RT-PCR, and compared to matched healthy controls. Results. The results showed an unexpected increase in mRNA levels of both BDNF and ARTN in patients with GAD, that appeared almost doubled when compared to healthy controls. In comparison, both BDNF and ARTN are reduced in patients with major depressive disorder. Further, the results are intriguing and might involve distinguishing pathophysiological pathways. Conclusions. This is the first report of increased levels of a neurotrophic factor and of a glial cell line-derived neurotrophic factor family member in GAD patients. While further studies to confirm these results and the functional meaning in terms of pathophysiology of GAD are needed, the potential conceptual and clinical meanings are discussed.
\end{abstract}

Key words: GAD, major depression, BDNF, artemin, drug-naïve

(Received 11 November 2013; accepted 15 April 2014)

\begin{abstract}
Introduction
Generalized anxiety disorder (GAD) is a psychiatric disorder, characterized by pervasive anxiety, dysfunctional worries, nervous and motor strain, autonomic hyperactivity and hyper arousal (DSM 5.0, APA 2013). These symptoms largely overlap with major depressive disorder (MDD). Furthermore, at least seventy per cent of patients with a history of anxiety also presented a history of depression and at least half of the subjects with a history of depression also presented an anxiety disorder in their life. In most cases, anxiety comes before depression or at the same time (Moffitt et al. 2007). Despite these common symptoms, GAD and MDD are two clinically distinguishable disorders so that DSM 5.0 (APA 2013) have decided, based on clinical evidences, to keep them distinguished.

Although neuroplasticity-based studies have quite clearly elucidated the role of both neural and glial factors in depression, studies in anxiety disorders are still lacking.

In fact, in depressed patients, a reduction of brain-derived neurotrophic factor (BDNF) plasma levels in MDD, in comparison to healthy controls, has been consistently reported,
\end{abstract}

Correspondence: Stefano Pallanti, Department of Neuroscience, Psychology, Drug Research and Child Health - Neurofarba. Psychiatry Section, University of Florence, via delle Gore 2 H, 50100 Florence, Italy. Tel: +390554298459. E-mail: stefanopallanti@yahoo.it while effective pharmacological treatment correlates with a normalization (Lee and Yong 2008; Sen et al. 2008). Consistent with these clinical pharmacological studies, animal models have shown that knock-out mice for BDNF receptor had impaired neurogenesis, showing symptoms of depression and anxiety with no response to antidepressant treatment, while response to treatment has been correlated with $\mathrm{BDNF}$ receptor on neuronal progenitor cells (NPCs) in mice, indicating an increase in neurogenesis (Ruan et al. 2014).

All these converging evidences suggest that BDNF might be at the center of many synaptic changes in the brain before, during, and after a depressive episode and that selective serotonin reuptake inhibitors (SSRIs) promote neurogenesis (Gonul et al. 2011).

Evidence of glial modulation in mood disorders has also been reported in post-mortem and imaging studies, where a reduction of glial elements in different brain areas has been evidenced in mood disorders (Schwarz and Bilbo 2012), with a significant decrease of glial cell line-derived neurotrophic factor (GDNF) during depressive episodes when compared to healthy controls, and a normalization after effective antidepressant treatment (Zhang et al. 2008). Furthermore, a reduction in GDNF levels in whole blood concentration has been noticed in patients with MDD or bipolar disorder (BD), in a partial or total remissive state as well (Takebayashi et al. 2006). 
Using quantitative real/time PCR method in peripheral blood cells, reduced expression levels of GDNF, artemin (ARTN), and neurotrophic factor 3 (NT-3) mRNAs were found in patients with major depressive disorder in a current depressive state, but not in a remissive state: this has been interpreted as a phase-related phenomenon. Altered expressions of these mRNAs were not found in bipolar disorder patients. Changes in the expression levels of GDNF, ARTN, and NT-3 mRNAs have been interpreted as state-dependent and associated with the pathophysiology of major depression (Otsuki et al. 2008).

Both GDNF and ARTN can link the GDNF family receptor $\alpha 1$ (GFR $\alpha 1$ ), and a change in the action of this receptor, in subjects with MDD, has been hypothesized to be correlated to a depressive episode (Otsuki et al. 2008). Moreover, a recent preclinical study described the antidepressant-like effect of ARTN when injected by the intracerebroventricular route in mice (Di Cesare Mannelli et al. 2011).

While the reduction of neurotrophin levels during a depressive episode has been consistently reported as well as an increase of these in response to treatments, studies conducted in a population under chronic or acute stress or anxiety disorders show split results.

Circulating nerve growth factor (NGF) is modified after exposure to stressful acute or chronic events (Alleva et al. 1996a, 1996b; Aloe et al. 1994), and an increase in blood NGF levels during an acute stressful event such as parachute jumping has been reported (Aloe et al. 1994).

In a study comparing 15 elderly caregivers experiencing chronic stress, assessed by the Perceived Stress Scale, and depressive symptoms assessed by Beck Depression Inventory Symptoms, in 15 healthy controls, doubled levels of NGF have been found in the caregivers (Hadjiconstantinou et al. 2001).

In the anxiety-stress area, the results are split; acute stress might reduce BDNF in patients with post-traumatic stress disorder (PTSD); in a study conducted on 18 patients with PTSD compared to 18 healthy subjects, BDNF levels appeared significantly reduced compared to the controls, while the number and temporal distance of the traumatic events had no influence (Dell'Osso et al. 2009). The lowest BDNF levels seem to be correlated with the greater treatment response to escitalopram, the most selective SSRI agent with putative neurotrophic effects, as seen in another PTSD study conducted on a sample group of 16 chronic PTSD patients (Berger et al. 2010).

In a large sample of 393 (66.7\% females) non-depressed, unmedicated patients with social anxiety disorder, panic disorder, agoraphobia, and GAD, BDNF levels were determined in comparison to 382 healthy controls ( $62.0 \%$ females). No differences in BDNF levels were reported between the patients and the controls, regardless of the type of anxiety disorder, but analyses stratified by gender revealed that female patients had lower levels of BDNF compared to female controls. This reduction appeared stronger in female patients with more than one anxiety disorder. In contrast, the BDNF levels were similar between male patients and controls, and unrelated to the clinical characteristics of anxiety (Molendijk et al. 2012). These results, if confirmed, might involve a gender-specific pattern.
To the best of our knowledge, there are no specific studies on glial cell-line derived neurotrophic factor family members in subjects with GAD.

The purpose of this study is to investigate ARTN and BDNF in drug-naïve patients presenting with episodes of generalized anxiety disorder (GAD), and without a history or current condition of depression, in comparison to healthy controls.

\section{Materials and methods}

At the Department of Neurosciences, Psychology, Drug Research and Child Health of the University of Florence, we studied 14 drug-naïve patients with generalized anxiety disorder (DSM IV-TR), comparing them to 10 ageand gender-matched healthy subjects. The subjects were excluded if under 18 or over 65 years old. Also, subjects with comorbidity, present or past history for another Axis I psychiatric disorder, as well as substance abuse, chronic diseases, inflammatory bowel diseases (IBD), atrophic gastritis, interstitial cystitis or neoplasia were excluded (Johansson et al. 2008; Kang et al. 2009; Liu et al. 2009; Shieh et al. 2010; Von Boyen et al. 2006). All subjects enrolled were drug-naïve. Use of psychopharmacological treatments including benzodiazepine or steroid therapy was excluded for the control sample as well. The study was accepted by the department IRB and the informed consent was obtained from all subjects.

All patients and healthy controls were subjected to a psychiatric interview following the SCID Clinician Version Interview: the patients' edition (First et al. 2002a) for the first and the non- patients' edition for the second (First et al. 2002b). All patients were administered the Hamilton Depression Rating Scale (HDRS) (Hamilton 1960) test and GAD - 7 (Spitzer et al. 2006) to assess the severity of depression and anxiety.

\section{Blood samples}

About 15-20 ml of venous blood was withdrawn from all 24 subjects between 8:00 a.m. and 9:00 a.m., treated with sodium heparin (500 UI heparin/ml blood), and conserved at $4^{\circ} \mathrm{C}$ for a maximum of $48 \mathrm{~h}$. Within that period of time, the isolation of lymphocytes was performed.

\section{Isolation of lymphocytes}

The blood samples were diluted 1:1 with PBS solution, mononuclear leukocytes were isolated by a gradient of centrifugation created according to Böyum's method using Separation Medium $^{\otimes}$ (MP Biomedicals, LLC) (Böyum 1968). The pellet obtained was stored at $-80^{\circ} \mathrm{C}$.

\section{$m R N A$ level analysis}

Mononuclear leukocyte mRNA was extracted using TRI - Reagent ${ }^{\circledast}$ (Sigma). The cDNA was obtained by using the iScript cDNA Synthesis $\mathrm{Kit}^{\circledR}$ (Bio Rad) according to the manufacturer's protocol. The mRNA for ARTN, BDNF and $\beta$-actin (ACTB) were amplified by GoTaq ${ }^{\circledR}$ Flexi DNA Polymerase 2,500u (Promega). The following human gene specific primers were used: BDNF (GenBank accession number: 
NM_001143816.1), forward: 5' TGGCTGACACTTTCGAACAC 3', reverse 5' AGAAGAGGAGGCTCCAAAGG 3', ARTN (GenBank accession number NM_001136215.1), forward 5' GCGGATCCCAGCCTAAAAG 3', reverse 5' CCAGTGCCAGAGTCTGTGAGA $3^{\prime}$ and ACTB (GenBank accession number: NM_001101.3), forward 5' GCGGGAAATCGTGCGTGACATT 3', reverse 5' GATGGAGTTGAAGGTAGTTTCGTG 3'.

The samples were subjected to 30 cycles of PCR performed using the following annealing temperatures: ARTN: $57^{\circ} \mathrm{C}$; BDNF: $56^{\circ} \mathrm{C}$; ACTB: $56^{\circ} \mathrm{C}$. The amplicons were separated by electrophoresis on a $1.5 \%$ agarose gel. Densitometric analysis was performed using the "ImageJ" analysis software and the results were normalized using ACTB as internal control. The mean expression levels of control subjects were arbitrarily fixed to $100 \%$.

\section{Statistic analysis}

The results were expressed as mean \pm S.E.M. and the analysis of variance was performed by ANOVA. A Bonferroni's significant difference procedure was used as post-hoc comparison. $P$ values of less than 0.05 were considered as significant. Data were analyzed using the "Origin 8.1" software.

\section{Results}

Main results: The PCR analysis showed that measures of both BDNF and ARTN levels are increased in the peripheral white blood cells of GAD patients compared to the normal control; mRNA BDNF expression levels in peripheral white blood cells of patients with GAD significantly increased in GAD patients $(186.74 \% \pm 23.71 \%)$ in respect of healthy subjects fixed to $100 \%$ (Figure 1), and the same increase, even more evident, was observed for mRNA ARTN levels

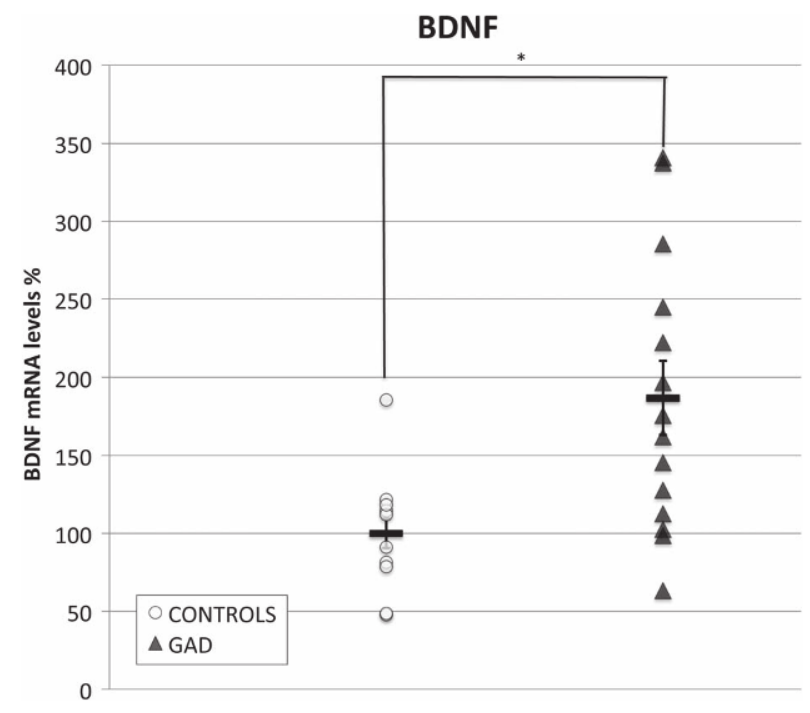

Figure 1. mRNA levels of BDNF in the two populations. The PCR analysis shows a significant increase of this factor in GAD compared to the controls. Densitometric analysis was performed and the results were normalized using $\beta$-actin as an internal control. The mean of BNDF expression level of control subjects is arbitrarily fixed to $100 \%$. Mean \pm S.E.M. is reported. $* P<0.05$.
$(229.18 \% \pm 28.63 \%)$ (Figure 2), where the ARTN level was more than double that in the healthy controls. Table I shows demographic and clinical characteristics of the subjects. The mean levels of HDRS and GAD - 7 in two groups of patients are well differentiated. The HDRS mean value in the GAD group was $(9.00 \pm 0.47)$, while the mean value for GAD 7 was $(19.64 \pm 0.70)$ in GAD, showing no comorbidity with a depressive spectrum disorder. The SCID clinical version interview verified that no other psychiatric disorder had occurred in the past.

The mean levels of HDRS for the controls were $(2.20 \pm 0.39)$ and $(2.80 \pm 0.44)$ for the GAD -7 scale at the time of sampling. No psychiatric disorders had occurred in the past.

No subject was under medication at the time of sampling or presented a chronic inflammatory disease, neoplasia or drug or alcohol abuse.

A difference must be reported between the mean ages of the two groups: GAD $(42.29 \pm 2.74)$ versus $(34.00 \pm 3.10)$ in the control group.

\section{Conclusion}

The results show, unexpectedly, substantial doubling in the levels of both BDNF and ARTN in the GAD subjects compared to the healthy controls.

This is the first study measuring BDNF and ARTN peripheral blood levels in GAD drug-naïve patients without depression.

No correlation has been proved between the severity of GAD assessed with the GAD-7 scale and the level of neurotrophins.

Several antidepressant and anxiolytic treatments have been reported modulating neurotrophins in depression. To our knowledge, the only study in GAD patients was a double blind duloxetine versus placebo regulatory study

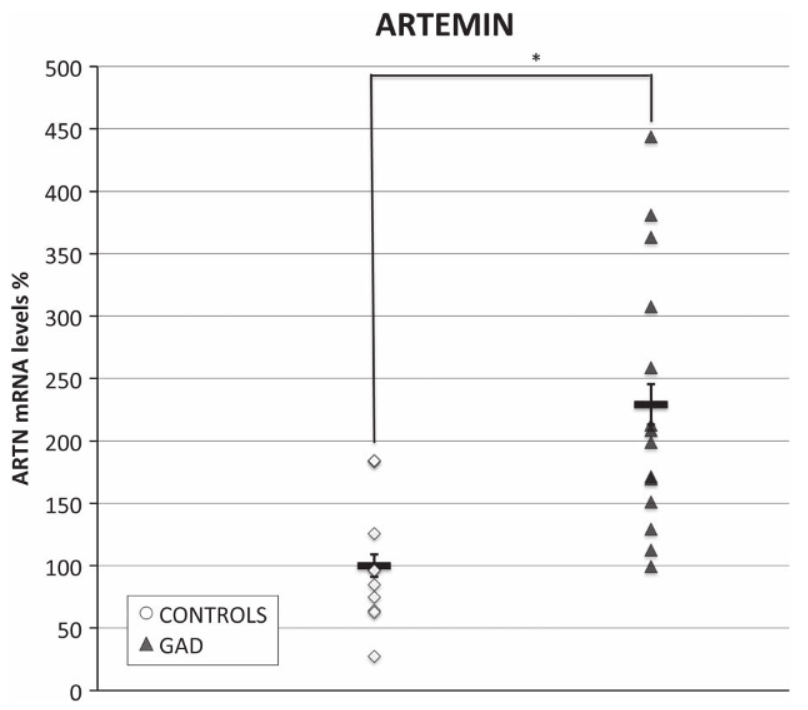

Figure 2. mRNA levels of ARTN in the two populations. The PCR analysis shows a significant increase of this factor in GAD compared with healthy controls. Densitometric analysis was performed and the results were normalized using $\beta$-actin as an internal control. The mean of ARTN expression level of control subjects is arbitrarily fixed to $100 \%$. Mean \pm S.E.M. is reported. ${ }^{*} P<0.05$. 
Table I. Demographic and clinical characteristics of GAD patients.

\begin{tabular}{llcrc}
\hline Patients & Sex & Age of onset & HAM - D & GAD - 7 \\
\hline GAD 1 & M & 26 & 11 & 20 \\
GAD 2 & F & 24 & 12 & 21 \\
GAD 3 & F & 30 & 9 & 19 \\
GAD 4 & M & 32 & 8 & 19 \\
GAD 5 & M & 40 & 8 & 21 \\
GAD 6 & F & 38 & 8 & 21 \\
GAD 7 & F & 32 & 8 & 21 \\
GAD 8 & M & 30 & 9 & 21 \\
GAD 9 & F & 32 & 11 & 19 \\
GAD 10 & F & 30 & 11 & 20 \\
GAD 11 & F & 17 & 10 & 21 \\
GAD 12 & F & 36 & 8 & 21 \\
GAD 13 & M & 40 & 7 & 20 \\
GAD 14 & M & 45 & 6 & 11 \\
\hline
\end{tabular}

on $210 \mathrm{GAD}$ patients, in which the treatment response to duloxetine $(60 \mathrm{mg})$ and BDNF plasma levels were studied before the randomization and after 15 weeks of treatment (Ball et al. 2013). After 7 weeks, subjects who did not respond to duloxetine had an augmentation of the daily dose (from 60 to $150 \mathrm{mg}$ ). At the end of the 15 weeks of therapy, the responders showed an increase of BDNF levels, while no significant difference in baseline levels were observed in the non-responders and placebo groups (Ball et al. 2013). Unfortunately, the study does not report comparison with healthy controls either at the baseline or in the follow up, therefore these results cannot be easily interpreted.

Our sample comprised drug-naïve subjects and therefore present or past treatment could not be involved. Since the first line treatment for GAD includes treatment which is also used for the treatment of depression (Baldwin et al. 2012), follow up data about treatment response and correlation with neurotrophin levels would be of great interest. Follow up data are not yet available but further studies will report them. While presence of a history of comorbid depression in our sample was an exclusion criterion, in the regulatory study above, this feature was not considered. Furthermore, the sample considered in the Ball study (Ball et al. 2013) comprised only Chinese subjects, therefore ethnic differences might explain our different results in a Caucasian sample.

To the best of our knowledge, there are no other studies on GAD involving neurotrophins. A broader study was done in which BDNF levels in the entire spectrum of anxiety disorders show a difference in serum levels between female patients and the same gender controls, with the neurotrophic factor appearing decreased in the first group, while no change could be appreciated between male patients versus male controls, leading the authors to suggest that this difference may play a role in the physiopathology of anxiety (Molendjik et al. 2012). A gender based stratification is therefore recommended.

In our small sample, we did not find significant genderrelated differences in the population considered. The difference in age between the group with the GAD average greater than the control might have some influences, even if evidence about the impact of age on the BDNF levels are puzzling (Bus et al. 2011), but in any case, the difference of age in our sample could not account for such a relevant difference in the results; a further larger study should consider not only age but smoking status, alcohol consumption and more generally the lifestyle, as well as perceived stress and stressful events (Hadjicostantinou et al. 2001).

BDNF is not only considered to be a neurotrophin but also an immunotrophin, epitheliotrophin and metabotrophin (Chaldakov et al. 2007) as well as glia belonging to a complex network regulated by neurotransmitters and cytokines that intervene in neurotrophic processes. In particular, interleukins (IL) appear interesting since many studies have shown a consistent role of inflammatory mediators in psychiatric diseases (Barres 2003).

Variations in the levels of pro-inflammatory interleukins have been noticed in chronic states of anxiety (Gill et al. 2008; Hoge et al. 2009) as well. These variations involve, in patients with GAD, increased levels of tumor necrosis factor- $\alpha$ (TNF- $\alpha$ ) and IL-17, and a reduction in IL-4 and IL-10 (Vieira et al. 2010) and increased vulnerability to viral diseases have been reported (Arranz et al. 2007; Takkouche et al. 2001); further studies would consider peripheral levels of several pro-inflammatory and anti-inflammatory cytokines (IL-2, IL-6 e IL-10) in relation with glial and neural factors in GAD.

We checked the results obtained in the same laboratory comparing the plasma levels of BDNF and ARTN of a sample of 9 patients with major depression (DSM IV TR, APA 2000), the severity of symptoms assessed by the Hamilton Depression Rating Scale (mean values $23.00 \pm 1.36$ ); results were not only consistent with the literature (Sen et al.2008; Otsuki et al. 2008), but also show the mean level of both BDNF (66.79 \pm 9.33 vs. $186.74 \pm 23.71 \%$ in GAD) and ARTN ( $42.56 \pm 8.86$ vs. $229.18 \pm 28.63 \%$ in GAD) reduced in depressed patients compared both to the normal and to the present GAD subjects where BDNF was 3 times higher and ARTN more than 5 times higher.

This further comparison enhances the meaning of the results, and, if replicated, highlight the difference between GAD and depression, with the only limitation of the sample dimension.

The results for mRNA level of BDNF and ARTN cannot be generalized to studies in serum, plasma, platelet or in the brain, and the correlation between growth factor alterations in peripheral blood and in the central nervous system is still poorly understood. In future studies, the measurements of serum BDNF and ARTN protein levels could complement the present evidence of increased mRNA levels of these factors. Furthermore, it remains to be established whether there is a correlation between growth factor alterations in peripheral blood and in the central nervous system (cerebro-spinal fluid), and if environmental factors affect the expression of these factors also at the brain level.

Although this population cannot be interpreted as representative of the "real world" GAD patients, generally highly comorbid, these data are extremely clear as a concept of proof, and if replicated, they will draw a line at the level of neuroplasticity phenomena between anxiety and depression. 


\section{Key points}

1. Evidence of nervous growth factor alteration in GAD is lacking.

2. The present study was performed on drug- naïve GAD patients.

3. BDNF and ARTN mRNA levels were significantly increased in patients with GAD, in comparison to the healthy control subjects.

\section{Acknowledgements}

Financial support for the research was obtained from the Italian Ministry of Scientific Research, University of Florence and from CNS onlus Firenze (IT). The authors declare that they have no financial competing interests.

\section{Statement of interest}

None of the authors reports conflicts of interest.

\section{References}

Alleva E, Petruzzi S, Cirulli F, Aloe L. 1996a. NGF regulatory role in stress and coping of rodents and humans. Pharmacol Biochem Behav 54:65-72.

Alleva E, Aloe L, Cirulli F, Della Seta D, Tirassa P. 1996b. Serum NGF levels increase during lactation and following maternal aggression in mice. Physiol Behav 59:461-466.

Aloe L, Bracci-Laudiero L, Alleva L, Lambiase E, Micera A, Tirassa P. 1994. Emotional stress induced by parachute jumping enhances blood nerve growth factor levels and the distribution of nerve growth factor receptors in lymphocytes. Proc Natl Acad Sci USA 91:10440-10444.

American Psychiatric Association (APA). 2000. Diagnostic and statistical manual of mental disorder IV Text Revised. American Psychiatric Publishing.

American Psychiatric Association (APA). 2013. Diagnostic and statistical manual of mental disorder V. American Psychiatric Publishing.

Arranz L, Guayerbas N, De la Fuente M. 2007. Impairment of several immune functions in anxious women. J Psychosom Res 62:1-8.

Baldwin DS, Allgulander C, Bandelow B, Ferre F, Pallanti S. 2012. An international survey of reported prescribing practice in the treatment of patients with generalized anxiety disorder. World. J Biol Psychiatry 13:510-516.

Ball S, Marangell L, Lipsius S, Russel J. 2013. Brain-derived neurotrophic factor in generalized anxiety disorder: results from a duloxetine clinical trial. Prog Neuropsychopharmacol Biol Psychiatry 43C:217-221.

Barres BA. 2003. What is a glial cell?. Glia 43:4-5.

Berger W, Mehra A, Lenoci M, Metzler TJ, Otte C, Tarasovsky G, et al. 2010. Serum brain-derived neurotrophic factor predicts responses to escitalopram in chronic posttraumatic stress disorder. Prog Neuropsychopharmacol Biol Psychiatry 34: 1279-1284.

Böyum A. 1968. Separation of leukocytes from blood and bone marrow. Introduction. Scand J Clin Lab Invest Suppl 97:7.

Bus BA, Molendijk ML, Penninx BJ, Buitelaar JK, Kenis G, Prickaerts J, et al. 2011. Determinants of serum brain-derived neurotrophic factor. Psychoneuroendocrinology 36:228-229.

Chaldakov GN, Fiore M, Tonchev AB, Dimitrov D, Pancheva R, Rancic G, et al. 2007. Homo obesus: a metabotrophin-deficient species. Pharmacology and Nutrition Insight. Curr Pharm Des 13:2176-2179.

Dell'Osso L, Carmassi C, Del Debbio A, Dell'Osso MC, Bianchi C, da Posso E, et al. 2009. Brain-derived neurotrophic factor plasma levels in patients suffering from post-traumatic stress disorder. Prog Neuropsychopharmacol Biol Psychiatry 33:899-902.
Di Cesare Mannelli L, Vivoli E, Salvicchi A, Schiavone N, Koverech A, Messano M, et al. 2011. Antidepressant-like effect of artemin in mice: a mechanism for acetyl-L-carnitine activity on depression. Psychopharmacology 218:347-356.

First MB, Spitzer RL, Gibbon M, Gibbon W, Janet BW. 2002a. Structured Clinical Interview for DSM-IV-TR Axis I Disorders, Research Version, Patient Edition With Psychotic Screen (SCIDI/P W/PSY SCREEN) New York: Biometrics Research, New York State Psychiatric Institute.

First MB, Spitzer RL, Gibbon M, Gibbon W, Janet BW, et al. 2002b. Structured Clinical Interview for DSM-IV-TR Axis I Disorders, Research Version, Non-patient Edition. (SCID-I/NP) New York: Biometrics Research, New York State Psychiatric Institute.

Gill J, Vythilingam M, Page G. 2008. Low cortisol, high DHEA, and high levels of TNF- $\alpha$ and IL-6 in women with PTSD. J Traumatic Stress 21:530-539.

Gonul AS, Kitis O, Eker MC, Eker OD, Ozan E, Coburn K. 2011. Association of the brain-derived neurotrophic factor Val66Met polymorphism with hippocampus volumes in drug-free depressed patients. World J Biol Psychiatry 12:110-118.

Hadjiconstantinou M, McGuire L, Duchemin AM, Laskowski B, Klecolt-Glaser J, Glaser R. 2001. Changes in plasma nerve growth factor levels in older adults associated with chronic stress. J Neuroimmunol 116:102-106.

Hamilton M. 1960. A rating scale for depression. J Neurol Neurosurg Psychiatry 23:56-62.

Hoge EA, Brandstetter K, Moshier S, Pollack MH, Wong KK, Simon NM. 2009. Broad spectrum of cytokine abnormalities in panic disorder and ptsd. Depress Anxiety 26:447-455.

Johansson M, Jönsson M, Norrgård O, Forsgren S. 2008. New aspects concerning ulcerative colitis and colonic carcinoma: analysis of levels of neuropeptides, neurotrophins, and TNFalpha/TNF receptor in plasma and mucosa in parallel with histological evaluation of the intestine. Inflamm Bowel Dis. 14:1331-1340.

Kang J, Perry JK, Pandey V, Fielder GC, Mei B, Qian PX, et al. 2009. Artemin is oncogenic for human mammary carcinoma cells. Oncogene 28:2034-2045.

Lee HY, Yong KK. 2008. Plasma Brain-derived neurotrophic factor as a peripheral marker of the action of antidepressants. Neuropsychobiology 57:194-199.

Liu HT, Tyagi P, Chancellor MB, Kuo HC. 2009. Urinary nerve growth factor level is increased in patients with interstitial cystitis/bladder pain syndrome and decreased in responders to treatment. BJU Int 104:1476-1481.

Moffitt TE, Harrington H, Caspi A, Kim-Cohen J, Goldberg D, Gregory AM, et al. 2007. Cumulative and sequential comorbidity in a birth cohort followed prospectively to age 32 years. Arch Gen Psychiatry 64:651-660.

Molendijk ML, Bus BA, Spinhove P, Penninx BW, Prickaerts J, Oude V, et al. 2012. Gender specific associations of serum levels of brain-derived neurotrophic factor in anxiety. World J Biol Psychiatry 13:535-43.

Otsuki K, Uchida S, Watanuki T, Wakabayashi Y, Fujimoto M, Matsubara T, et al. 2008. Altered expression of neurotrophic factors in patients with major depression. J Psychiatr Res 42:1145-1153.

Ruan L, Lau BW, Wang J, Huang L, Zhuge Q, Wang B, et al. 2014. Neurogenesis in neurological and psychiatric diseases and brain injury: from bench to bedside. Prog Neurobiol 115:116-137.

Schwarz JM, Bilbo SD. 2012. Sex, glia and development: interactions in health and disease. Horm Behav 62:243-253.

Sen S, Duman R, Sanacora G. 2008. Serum brain-derived neurotrophic factor, depression, and antidepressant medications: meta - analyses and implications. Biol Psychiatry 64:527-532.

Shieh KR, Yi CH, Liu TT, Tseng HL, Ho HC, Hsieh HT, Chen CL. 2010. Evidence for neurotrophic factors associating with TRPV1 gene expression in the inflamed human esophagus. Neurogastroenterol Motil 22:971-977.

Spitzer RL, Kroenke K, Williams JB, Lowe B. 2006. A brief measure for assessing generalized anxiety disorder. Arch Intern Med 166:1092-1097. 
Takebayashi M, Hisaoka K, Nishida A, Tsuchioka M, Miyoshi I, Kozuru T, et al. 2006. Decreased levels of whole blood glial cell line-derived neurotrophic factor (GDNF) in remitted patients with mood disorders. Int J Neuropychopharmacol 9:607-612.

Takkouche B, Regueira C, Gestal-Otero JJ. 2001. A cohort study of stress and the common cold. Epidemiology 12:345-349.

Vieira MM, Ferreira TB, Pacheco PA, Barros PO, Almeida CR, Araújo-Lima CF, et al. 2010. Enhanced Th17 phenotype in individuals with generalized anxiety disorder. J Neuroimm 229:212-218.
Von Boyen GB., Steinkamp M, Geerling I, Reinshagen M, Schäfer KH, Adler G, et al. 2006. Proinflammatory cytokines induce neurotrophic factor expression in enteric glia: a key to the regulation of epithelial apoptosis in Crohn's disease. Inflamm Bowel Dis 12:346-354.

Zhang X, Zhang Z, Xie C, Xi G, Zhou H, Zhang Y, et al. 2008. Effect of treatment on serum glial cell line-derived neurotrophic factor in depressed patients. Prog Neuropsychopharmacol Biol Psychiatry 32:886-890. 